Popularity as an Organizing Factor of Preadolescent Friendship Networks:

Beyond Prosocial and Aggressive Behavior

Handrea A. Logis

Philip C. Rodkin

University of Illinois at Urbana-Champaign

Scott D. Gest

Pennsylvania State University

Hai-Jeong Ahn

Korean Educational Development Institute

\title{
December 30, 2012
}

Please cite as: Logis, H., Rodkin, P. C., Gest, S. D., \& Ahn, H.-J. (2013). Popularity as an organizing factor of preadolescent friendship networks: Beyond prosocial and aggressive behavior. Journal of Research on Adolescence. 
Author Note

Handrea A. Logis, Department of Educational Psychology, University of Illinois at Urbana-Champaign; Philip C. Rodkin, Departments of Educational Psychology and Psychology, University of Illinois at Urbana-Champaign; Scott D. Gest, Department of Human Development and Family Studies, Pennsylvania State University; Hai-Jeong Ahn, Korean Educational Development Institute.

We are grateful to the children, teachers, and school principals who participated in and contributed to this project. This research was supported by grants to the second and third authors from the Institute of Education Sciences (\#R305A100344) and from the William T. Grant and Spencer Foundations (\#200900174).

Correspondence concerning this article may be addressed to Handrea A. Logis, 240A Col. Wolfe School, Mail Code 422, 403 E. Healey St., University of Illinois, Champaign, Illinois. Email: hlogis2@illinois.edu 


\begin{abstract}
This study investigates friendship selection and influence processes in relation to popularity, aggression, and prosociality among 613 fifth graders in 26 classrooms within one academic year. Results showed that youth tended to select their friends based on similarity in popularity more than similarity in aggression or prosociality. Aggressive youths tended to select prosocial peers as friends given similarity in popularity, but prosocial youths did not disproportionately nominate aggressive peers. Socialization within friendships was evident for aggressive and prosocial behavior and popularity. Discussion considers the importance of social status as a grouping mechanism in peer social ecologies, and as a malleable factor that can impact student adjustment.
\end{abstract}

Keywords: friendship, aggression, prosociality, popularity, social network 
Popularity as an Organizing Factor of Preadolescent Friendship Networks:

Beyond Prosocial and Aggressive Behavior

Popularity reflects one's visibility and dominance. It is a reputation ascribed to someone based on social consensus (Bukowski, 2011; Cillessen \& Marks, 2011). As Bukowski (2011, p.11) put it: a "popular person stands out and fits in at the same time." Being popular has been associated with both prosocial characteristics such as being cooperative and kind, and with aggressive behaviors such as starting fights and being mean (Cillessen \& Rose, 2005; Rodkin, Farmer, Pearl, \& Van Acker, 2000).

The importance of popularity in adolescent peer relationships is well established. Adolescents are willing to compromise friendship and affection to gain popularity (LaFontana \& Cillessen, 2010). Youths also tend to select their friends based on similarity in popularity (Berger \& Dijkstra, 2013; Dijkstra, Berger, \& Lindenberg, 2011; Dijkstra, Cillessen, \& Borch, 2012; Witvliet et al., 2010; but see Mathys, Burk, \& Cillessen, 2013). Recent studies shed light on how popularity organizes adolescent social interactions, but most of these studies use longitudinal designs focused on changes across grade levels. Less is known about how selection and socialization processes operate within an academic year, particularly in preadolescence when popularity may not be as developmentally distinct from social preference (Rodkin, Ryan, Jamison, \& Wilson, 2012). Also missing from previous studies is consideration of behavioral heterogeneity among popular youths, such as those who are aggressive and those who are prosocial (de Bruyn \& Cillessen, 2006; Rodkin et al., 2000). If similarity in popularity is more important for friendship formation than similarity in prosocial or aggressive behaviors, then it seems possible that aggressive and prosocial youths of similar popularity levels might also select one another as friends (Farmer et al., 2002). 
The present study uses a sample of fifth-grade classrooms sampled three times over the course of an academic year. We examined whether (1) youths select friends based on similarity in popularity, (2) aggressive and prosocial youths who are of similar popularity tend to befriend one another, and (3) youths become more like their friends on aggression, prosocial behavior, and popularity.

\section{Selection Based on Similarity in Popularity}

Based on previous findings on the prominent effect of popularity homophily, we expected that preadolescents would select their friends based on similarity in popularity more than similarity in aggressive and prosocial behavior across the academic year (Hypothesis 1), but that aggressive and prosocial behavior would show independent selection effects. Dijkstra et al. (2011) examined changes between fifth and sixth grade friendship networks, finding that selection based on similarity in aggression disappeared when controlling for network structures, gender, and popularity. Likewise, a cross sectional study among fourth to sixth graders showed that affiliated youths were more similar with respect to their popularity than behavior (Witvliet et al., 2010). Friends are similar in aggression (Bagwell, Coie, Terry, \& Lochman, 2000; Cairns, Cairns, Neckermann, Gest, \& Gariépy, 1988; Kupersmidt, DeRoiser, \& Patterson, 1995; Patterson, Reid, \& Dishion, 1992; Poulin \& Boivin, 2000), but aggression homophily might be overestimated when popularity and other endogenous network structures are not accounted for. There is also homophily on prosocial behavior (Haselager, Hartup, van Lieshout, \& RiksenWalraven, 1998; Newcomb \& Bagwell, 1995), but less is known about whether prosocial homophily might also disappear with popularity accounted for. The present study investigated friendship formation based on similarity in popularity, aggression, and prosociality simultaneously. 


\section{Friendships among Aggressive and Prosocial Youths with Similar Popularity Levels}

Popular youths include those who are highly aggressive and those who are highly prosocial (de Bruyn \& Cillessen, 2006; Rodkin et al., 2000). Recent studies suggest that similarity in popularity is a better predictor of friendship formation than similarity in behavior. To the extent that this is the case, then friendships between aggressive and prosocial youths seem possible if they share similar popularity status. However, the contrasting behavioral styles of prosocial and aggressive youths may moderate the tendency to become friends with similarly popular classmates. For example, prosocial-popular youths may perceive friendships with aggressive-popular classmates as involving undesirable risks of conflict. In contrast, aggressivepopular youths may find friendships with prosocial-popular classmates particularly desirable as sources of positive friendship supports without the need to sacrifice status. Based on recent findings underscoring the importance of popularity in friendship formation, we hypothesized that prosocial-popular youth would be reluctant to form friendships with aggressive-popular classmates, but that aggressive-popular youth would be particularly attracted to prosocialpopular classmates (Hypothesis 2).

\section{Socialization of Aggression, Prosociality, and Popularity}

Peer groups are powerful contexts for socialization among youths. Affiliation with aggressive peers is associated with increases in one's own level of aggression (Dishion \& Tipsord, 2011; Espelage, Holt, \& Henkel, 2003; Sijtsema et al., 2010), and friendship with prosocial peers is associated with increases in one's prosocial behavior (Barry \& Wentzel, 2006; Berger \& Rodkin, 2012). Meanwhile, friendships with highly popular peers can improve one's own status over time (Dijkstra, Cillessen, Lindenberg, \& Veenstra, 2010; Dijkstra et al., 2012), beyond the effects of changes in one's aggressive and prosocial behavior (Marks, Cillessen, \& 
Crick, 2012). Together, these findings suggest that youths may become more like their friends with respect to behavior and status. We expected that influence effects for aggression, prosociality, and popularity among fifth grade friendship networks would be positive and significant (Hypothesis 3).

\section{Study Overview}

The goal of this study is to examine friendship selection and socialization for aggression, prosociality, and popularity, controlling for gender and preference, from the beginning to the end of an academic year among fifth grade youths. We hypothesized that (1) youths would establish and maintain friendships based on similarity in popularity more than similarity in aggressive and prosocial behavior, (2) the popularity-similarity effect would be evident even in dyads comprised of behaviorally dissimilar youth, and (3) there would be significant influence effects for aggression, prosocial behavior, and popularity.

\section{Method}

\section{Participants}

This study is part of a larger longitudinal project of teaching practices, classroom peer ecologies, and youth outcomes with two developmental components: (i) a cross-sectional comparison between first, third, and fifth grade classrooms, and (ii) three repeated assessment waves within a school year. Because the current focus is on preadolescents' friendships, only data from fifth grade classrooms were included for analysis. Data were collected in the first weeks of school (September-October: Time 1 or T1), approximately two months later (November-December: Time 2 or T2), and near the end of the school year (April-May: Time 3 or T3) in equal proportions across two study sites (urban areas in Illinois/Indiana, rural areas in Pennsylvania). Parental consents and student assents were required for participation in the study. 
Of 764 total students across two years of data collection in 34 fifth-grade classrooms in 13 schools from two study sites, 639 students participated at least once across three time points: 585 participated at T1, 602 at T2, and 591 at T3 $(53 \%$ boys; $\mathrm{M}$ age $=10.71$ years, $\mathrm{SD}=0.42)$. The ethnic composition across the entire sample was 57\% European American, 26.5\% African American, 6.8\% Hispanic, 2.9\% Asian, and 2.2\% classified as "Other," although participants from the Pennsylvania site were predominately European American.

\section{Procedure}

Participants completed a survey that took approximately 45 minutes as a group during a regular class period. To maximize privacy, students placed standing folders around their desks to cover their responses. Participants were reassured that their answers were confidential and that participation was voluntary. A graduate research assistant read aloud instructions and questions while the students followed along and responded to the questions. At least two trained assistants were present to assure privacy and to assist participants.

\section{Measures}

Participants answered peer nomination questions that were followed by a list of all students' names in their classroom. They were allowed to nominate as many classmates as they wanted or to skip the question if no one fit the description.

Friendship networks. Participants were asked to nominate classmates whom they perceived as friends. On average, participants nominated 7.19 friends at $\mathrm{T} 1,7.00$ at $\mathrm{T} 2$, and 7.45 at T3. Friendship networks were characterized by low density, high reciprocity, and high transitivity (see Table 1). Friendship networks were largely complete (missing fraction 10-12\%) and had relatively few changes in membership (> 90\% Stayers). The Jaccard indices indicated a similar amount of friendship change across the two periods $(.59, .57)$, whereas the Hamming 
distance indicated a high number of changes in friendship nominations between time periods, permitting complex selection dynamic modeling in SIENA with adequate statistical power (see Veenstra \& Steglich, 2012; Veenstra, Dijkstra, Steglich, \& Van Zalk, 2013).

Aggression. Aggressive behavior measured in this study was meant to capture both overt and relational aggression. At T1, participants responded to two items, "These kids start FIGHTS," and "These kids SAY MEAN THINGS about other kids," in addition to, "These kids MAKE FUN of people" at T2 and T3. Proportion scores for each item were computed by counting the total number of nominations that each child received divided by the number of participants in the classroom. An average proportion score from the two items at T1 and the three items at T2 and T3 was computed to measure aggression for each student ( $\alpha$ 's $=.91, .92, .94$ at T1-3).

Prosociality. Participants responded to two items, "These kids COOPERATE" and “These kids are always willing to do something NICE for somebody else." Proportion scores for each item were calculated as indicated previously. An average proportion score from these two items was computed to measure prosociality for each student ( $\alpha$ 's $=.90, .80, .91$ at T1-3).

Popularity. Participants responded to an item, "These are the most POPULAR kids in my class." Proportion scores of popularity were calculated to measure popularity for each student.

Preference. Participants responded to the items "These are the kids whom I would LIKE MOST to play with" and "These are the kids whom I would LIKE LEAST to play with." Proportion scores for each item were computed. Preference was measured by calculating the proportion scores of like most minus like least.

Proportion scores for aggression, prosociality, popularity, and preference were zstandardized within gender because there were gender differences in the distribution of these 
variables. To fulfill SIENA computation requirements, these variables were transformed into discrete ordinal scales. Final analyses used 3-point scales: $\mathrm{z} \leq-0.5,-0.5<\mathrm{z}<0.5$, and $\mathrm{z} \geq 0.5$. This categorization was chosen for ease of interpretation, corresponding to low, average, and high. Separate analyses using 4-point scales (i.e., $\mathrm{z} \leq-0.5,-0.5<\mathrm{z} \leq 0.0,0.0<\mathrm{z}<0.5, \mathrm{z} \geq 0.5$ ) produced similar findings. Descriptive statistics for behaviors and status, the frequency of students in each category, and the number of students who changed their behaviors or status between time points are presented in Table 2. The fraction of stable actors showed that around $70 \%$ of students did not change their behaviors or status within a period. Distance represents the observed number of changes for aggression, prosociality, popularity, and preference between observation points, which is lower than for the network (6.15 - 7.85 as compared to 93.23 98.62), indicating that specification for the behavior dynamics needs to be more parsimonious than for the network dynamics.

\section{Analysis Strategy}

Analyses were conducted with stochastic actor-based models to estimate co-evolution of networks and behaviors through RSiena (Ripley, Snijders, Preciado, 2011). Because the size of our classrooms was rather small to obtain well-converged estimates when analyzed individually, classrooms were combined and analyzed simultaneously using the multi-group option, assuming that different classrooms were unrelated to one another except for having the same rules to evolve. The difference between meta-analysis and multi-group options is that with meta-analysis, each classroom is analyzed separately using the same model specification. Different parameter estimates from each classroom are then combined and interpreted. Hence, there is no assumption that each classroom produces the same parameter estimates. 
We first attempted to combine all 34 classrooms, but eight classrooms were excluded due to poor convergence (i.e., $t$-statistics $>0.1)$ or excessive missingness $(>30 \%)$ due to high mobility levels between observation points or low participation rates. Compared to the 26 included classrooms, the eight excluded classrooms did not differ systematically. SIENA allows compositional changes in the classroom across time, thus the final sample consisted of 613 students who had been enrolled at least once across the academic year within these 26 classrooms.

In examining friendship changes, we controlled for endogenous network structures suggested by Snijders, van de Bunt, and Steglich (2010), namely: outdegree, which represents the tendency to send ties; reciprocity, which reflects the tendency to have reciprocated ties; and transitivity, which denotes tendencies to form ties with friends of friends. Following Dijkstra et al. (2012), we examine selection and influence effects controlling for preference, in addition to gender, a highly salient feature in friendship selection (Kupersmidt et al., 1995).

Control variables. The selection effects controlled for outdegree, reciprocity, transitive ties, and balance. Gender was dummy coded as $1=$ Female. Selection based on homophily in gender and preference was taken into account by including in models same gender and similarity in preference effects. The effect of nomination received (ego) and given (alter) for gender and preference were included.

Selection effects. We included similarity effects for aggression, prosociality, and popularity, along with ego and alter effects for these variables. We expected that similarity effects for popularity would be larger than for aggressive and prosocial behavior (Hypothesis 1). To investigate whether the similarity effects for popularity were moderated by the behavioral composition of the dyad (Hypothesis 2), two interaction effects were included. These interactions 
tested whether the popular-similarity effects were different for aggressive (aggressive ego $\times$ prosocial alter $\times$ popular-similarity) and prosocial youths (prosocial ego $\times$ aggressive alter $\times$ popular-similarity).

Influence effects. Linear and quadratic shape effects for aggression, prosociality, and popularity were included as suggested by Snijders et al (2010). Friends' influence on behavior and popularity was estimated by the average similarity effect in SIENA, which can be interpreted as youths' tendency to be more like their friends in terms of aggression, prosociality, and popularity (Hypothesis 3). Effect preference and effect gender, indicating the main effects of preference and gender on changes in one's behaviors and popularity, were also included.

Parameter values in SIENA can be interpreted as the log odds ratio for choosing whether to change or not to change friendships, behaviors, or popularity (Snijders et al., 2010). Odds ratios can be obtained by calculating the exponential function of the parameter estimates. For the effects of behavioral variables (e.g., preference, aggression), the odds ratio is the exponential function of the estimate divided by two (i.e., number of categories minus one).

\section{Results}

\section{Descriptive Statistics}

Table 3 presents correlations among the main variables. As expected, popularity had a small positive correlation with aggression $(.03 \leq r \leq .17)$ and a somewhat stronger positive correlation with prosocial behavior $(.17 \leq r \leq .32)$. Preference was strongly correlated with popularity $(.50 \leq r \leq .61)$ and prosociality $(.50 \leq r \leq .64)$, but negatively correlated with aggression $(-.46 \leq r \leq-.31)$. Stability coefficients for popularity, aggression, prosociality, and preference were large $(.75 \leq r \leq .87)$.

\section{Network Structures, Gender, and Preference}


Table 4 presents the SIENA results. The negative outdegree effect indicates that youths were generally friends with fewer than half of their classmates. The positive reciprocity effect shows that friendships tended to be reciprocated. The positive transitive ties effect expresses the tendency for friends of friends to become friends and positive balance shows that youths tended to have friendships with those who have the same set of outgoing ties as them. The positive female ego and negative female alter effects together suggest that girls sent more friendship nominations, but received fewer than did boys. Youths were 1.45 times more likely to select same-gender rather than cross-gender friends as indicated by the positive same gender effect $(b=$ $0.37, t(577)=12.65, p<.001)$. The positive preference ego effect indicates that highly preferred youths sent more friendship nominations. Youths were 1.08 times more likely to select friends who had similar scores on preference as indicated through the similarity in preference effect $(b=$ $0.15, t(577)=2.12, p<.05)$.

\section{Friendship Selection for Aggression, Prosociality, and Popularity}

Ego effects. The positive ego effect for aggression indicates that aggressive youths sent more friendship nominations than other youths $(b=0.14, t(577)=3.58, p<.001)$.

Alter effects. The negative alter effect for aggression indicates a general tendency not to select aggressive youths as friends $(b=-0.11, t(577)=-3.54, p<.001)$. In contrast, the positive alter effect for popularity indicates that highly popular youths were 1.08 times more likely to receive friendship nominations as compared to their less popular peers $(b=0.15, t(577)=4.98, p$ $<.001)$.

Similarity effects. The effect of aggressive similarity was not significant, but the effect of prosocial similarity was significant $(b=0.21, t(577)=3.32, p<.001)$. The parameter estimate for popular similarity was larger than aggressive and prosocial similarity $(b=0.43$, 
$t(577)=7.39, p<.001)$, indicating that youths were 1.24 times more likely to nominate others who were similar in popularity as their friends. These findings are consistent with our first hypothesis that preadolescents would choose their friends based on similarity in popularity more than similarity in aggressive and prosocial behavior.

Moderation of popular-similarity effect. The interaction for aggressive ego $\times$ prosocial alter $\times$ popular-similarity was positive and significant $(b=0.16, t(577)=2.09, p<.05)$. This indicates that the popular-similarity effect was significantly stronger when aggressive youths were considering prosocial classmates as potential friends. The interaction for prosocial ego $\times$ aggressive alter $\times$ popular-similarity was negative but not significant $(b=-.08, t(577)=-0.93, p$ $=0.35$ ). To check whether aggressive youths tended to choose prosocial youths as friends regardless of whether they shared similar popularity levels, we ran an additional analysis with the interaction between aggressive ego $\times$ prosocial alter. This interaction was not significant.

\section{Socialization for Aggression, Prosociality, and Popularity}

The linear shape effect for prosocial behavior was negative and significant, indicating that the majority of youths in our sample scored below the mean on prosocial behavior. The quadratic shape effects for aggression, prosociality, and popularity were positive and significant, indicating that changes in both behaviors and popularity were self-reinforcing; youths with higher values would further increase, whereas those with lower values would further decrease their behaviors or popularity over the school year. All of the influence effects were positive and significant, indicating that youths became more similar to their friends in terms of aggression $(b$ $=3.53, t(577)=4.48, p<.001)$, prosociality $(b=3.66, t(577)=5.12, p<.001)$, and popularity $(b$ $=5.53, t(577)=5.10, p<.001)$. Table 5 shows that the maximum value in each row is at its diagonal, suggesting youths tended to change their behaviors and popularity in accordance with 
their friends. Effect preference on prosociality and popularity show that highly preferred youths tended to become more prosocial and popular over time.

Time heterogeneity. In supplementary analyses, we ran models separately from T1-T2 (Period 1) and T2-T3 (Period 2). Some effects were significant in both periods: Youths chose their friends based on similarity in popularity more than similarity in aggressive and prosocial behaviors; and influence effects for aggression, prosociality, and popularity were positive and significant. Other effects emerged only in Period 2: selection effects based on similarity in aggressive and prosocial behavior; and the moderation effect involving aggressive youth and the popular-similarity effect. These findings indicate that some dynamics emerge over the school year, but selection based on similarity in popularity and the influence effects for both behaviors and popularity are evident, even very early in the year.

\section{Discussion}

The idea that popularity becomes salient in peer relationships when youths enter a larger peer context such as middle school or high school has been widely tested (Sandstrom \& Cillessen, 2006). Studies that examine popularity as a grouping mechanism also have been conducted during the transition to middle school (Dijkstra et al., 2011, 2012). Popularity as a distinct force from preference has been more controversial when applied to the preadolescent years (Cillessen \& Marks, 2011; Rodkin et al., 2012). This study expands previous research on popularity homophily by analyzing these processes, controlling for preference, among fifth grade students across one academic year. The strength of popularity homophily was further investigated by examining friendships between aggressive and prosocial youths who have similar popularity levels. 
Consistent with Dijkstra et al. $(2011,2012)$ and Berger and Dijkstra (2013), we found that youths were more likely to choose their friends based on similarity in popularity than similarity in prosocial or aggressive behavior. Our study extends the work of Dijkstra et al. (2011, 2012) in showing that popularity functions as a grouping mechanism within a single academic year and before the transition to middle school. The fact that similarity in popularity emerged as a robust selection mechanism even after controlling for similarity in preference underscores that popularity and preference are distinct dimensions by $5^{\text {th }}$ grade. Examination between observation points revealed that popularity homophily occurred within the first two months of school and continued until the end of the school year.

We found that selection based on similarity in popularity was especially strong when aggressive youth were considering prosocial peers. This may indicate that similarity in popularity becomes especially important when aggressive youth are considering a friendship with a classmate whose behavior differs greatly from their own. In contrast, there was no evidence that the popular-similarity effect differed when prosocial youth considered aggressive peers. In some respects, the asymmetry in these results is consistent with Sijtsema, Lindenberg, and Veenstra's (2010) study that found some aggressive youths nominated prosocial peers as friends, but not vice versa. However, one must consider the full set of effects in our models when drawing conclusions about the tendency of prosocial-popular youths to form friendships with aggressive-popular peers: on the one hand, the positive popular-alter effect is balanced by the negative aggression-alter effect; on the other hand, this leaves the highly robust popularsimilarity effect suggesting that popular-prosocial youths may indeed select popular-aggressive youths as friends due to their similarity in popularity. 
Peer influence for aggression, prosociality, and popularity was significant across an academic year, indicating that youths become more like their friends in terms of both behaviors and popularity. The influence effect for popularity was also higher than for aggressive and prosocial behavior, suggesting that even among fifth graders, peer influence on popularity was prominent and could be observed within a school year. Popularity selection and socialization effects were found net of social preference, during a developmental period when popularity and preference have been held to be indistinct (Cillessen \& Marks, 2011). Conversely, although the priority youths place on popularity may grow during adolescence (LaFontana \& Cillessen, 2010), popularity socialization and selection effects are not always found among adolescent samples (see Mathys et al., 2013). Thus, the present investigation moves forward a developmental understanding of popularity as an organizer of peer social ecologies by revealing effects of popularity socialization and selection on friendship network formation within the course of one academic year; and demonstrating that these effects can be detected well before the onset of adolescence.

Also consistent with Dijkstra et al.'s (2012) findings is that highly popular youths tended to receive more friendship nominations. Studies have shown that popular youths have the power to set peer norms (Dijkstra, Lindenberg, \& Veenstra, 2008), to exert influence on others (Cohen \& Prinstein, 2006; Ellis \& Zarbatany, 2007; Shi \& Xie, 2012), and to gain access to resources (Hawley, 1999). With all these privileges that come with being popular, it is reasonable to find a subset of youths who will actively strive to gain popular status by trying to befriend popular peers. Correlations of popularity with aggression were positive and low, and with prosociality positive and somewhat stronger, which is in keeping with previous research involving this age range (Rodkin et al., 2000). 
The examination of both selection and influence effects using SIENA demonstrates that both are operative: in general, youths tend to select their friends based on similarity in both behaviors and popularity and to become more similar over time. Similar to Dijkstra et al. (2011), we did not identify a significant tendency for youths to select peers based on similarity in aggression, suggesting that initial similarity in friends' aggression is an indirect consequence of selection based on similarity on characteristics correlated with aggression (e.g., prosociality, preference, popularity). However, friends clearly became more similar in aggression over time, presumably due to socialization processes.

The present findings are specific to friendship selection and socialization processes for aggression, prosociality, and popularity in classroom contexts among fifth grade youths, after taking into account basic network structures, gender and preference. The inclusion of other demographic characteristics, academic achievement, relationship history, propinquity in the classroom, or extending the analyses to outside of the school setting (Veenstra \& Dijkstra, 2011) will offer a more differentiated story on how youths organize their social relationships with others. Future studies that incorporate measures of social goals in friendship selection and socialization may give better insight into how children make decisions in choosing their friends and changing their behaviors (Rodkin et al., 2012). With increasing work focusing on susceptibility and peer influence associated with popularity (Brechwald \& Prinstein, 2011; Schwartz \& Gorman, 2011; Shi \& Xie, 2012), future research could examine whether different subtypes of popular youths are susceptible to different peer influence and are exerting different types of behavior influence on others, or whether status differences between aggressive and prosocial youths moderate the direction of socialization. Another important future direction 
would be to examine popularity as a grouping mechanism in younger elementary school children (e.g., Schaefer, Light, Fabes, Hanish, \& Martin, 2010).

This study had several limitations. First, we were not able to include all classrooms in the analyses due to convergence problems. Second, the complexity of our models and the small size of our classrooms prevent us from analyzing SIENA results using meta-analysis, which would have enabled us to examine whether certain classroom network characteristics, such as density or classroom ethnic composition, contribute to socialization and selection mechanisms. Third, examination of time heterogeneity revealed that some parameter estimates vary between the two periods; more studies with multiple assessments within a single school year are necessary to clarify the time-dependent nature of particular effects. Finally, we focused on a specific form of moderation in this paper: additional moderators such as gender, preference, and dynamics in peer group affiliations may contribute to peer selection and influence mechanisms (Berger \& Rodkin, 2012; Peters, Cillessen, Riksen-Walraven, \& Haselager, 2010).

Aside from these limitations, the present study contributes to the literature by examining the role of popularity in preadolescents' friendship networks across one academic year. One implication from this study is that when popularity varies greatly from one student to another, a strong tendency to select friends based on similarity in popularity paired with a tendency to become more similar in popularity to friends over time may have the cumulative effect of strengthening status hierarchies in the classroom. Status hierarchies refer to the widely disparate levels of social status across students within a classroom or grade level and have been shown to promote the association between aggression and popularity (Garandeau, Ahn, \& Rodkin, 2011). Creating a more egalitarian classroom can be among the ways teachers intervene to inhibit the development of deviant peer norms (Ellis et al., 2012). Educators, through promoting new 
friendships, engaging students in cooperative activities, and identifying the latent social capital (what was called by Gronlund (1959) "leadership potential”) among high status children, have the potential to use peer social ecologies as a malleable factor to promote prosocial behavior and positive youth adjustment (Gest \& Rodkin, 2011). 


\section{References}

Bagwell, C. L., Coie, J. D., Terry, R. A., \& Lochman, J. E. (2000). Peer clique participation and social status in preadolescence. Merrill-Palmer Quarterly, 46, 280-305.

Barry, C. M., \& Wentzel, K. R. (2006). Friend influence on prosocial behavior: The role of motivational factors and friendship characteristics. Developmental Psychology, 42, 153163.

Berger, C., \& Dijkstra, J. K. (2013). Competition, envy, or snobbism? How popularity and friendships shape antipathy networks of adolescence. Journal of Research on Adolescence.

Berger, C., \& Rodkin, P. C. (2012). Group influences on individual aggression and prosociality: Early adolescents who change peer affiliations. Social Development, 21, 396-413.

Brechwald, W. A., \& Prinstein, M. J. (2011). Beyond homophily: A decade of advances in understanding peer influence processes. Journal of Research on Adolescence, 21, 166179.

Bukowski, W. M. (2011). Popularity as a social concept: Meanings and significance. In A. Cillessen, D. Schwartz, \& L. Mayeux (Ed.), Popularity in the peer system (pp.3-24). New York: Guilford.

Cairns, R. B., Cairns, B. D., Neckermann, H. J., Gest, S. D., \& Gariépy, J. L. (1988). Social networks and aggressive behavior-Peer support or peer rejection. Developmental Psychology, 24, 815-823.

Cillessen, A. H. N., \& Marks, P. E. L. (2011). Conceptualizing and measuring popularity. In A. Cillessen, D. Schwartz, \& L. Mayeux (Ed.), Popularity in the peer system (pp.25-56). New York: Guilford.

Cillessen, A. H. N., \& Rose, A. J. (2005). Understanding popularity in the peer system. Current 
Direction in Psychological Science, 14, 102-105.

Cohen, G. L., \& Prinstein, M. J. (2006). Peer contagion of aggression and health-risk behavior among adolescent males: An experimental investigation of effects on public conduct and private attitudes. Child Development, 77, 967-983.

de Bruyn, E.H, \& Cillessen, A. H. N. (2006). Popularity in early adolescence: Prosocial and antisocial subtypes. Journal of Adolescent Research, 26, 607-627.

Dijkstra J. K., Berger, C., \& Lindenberg, S. (2011). Do physical and relational aggression explain adolescents' friendships selection? The competing roles of network characteristics, gender, and social status. Aggressive Behavior, 37, 1-13.

Dijkstra, J. K., Cillessen, A.H.N., \& Borch, C. (2012). Popularity and adolescent friendship networks: Selection and influence dynamics. Developmental Psychology, doi: 10.1037/a0030098.

Dijkstra, J. K., Cillessen, A. H. N., Lindenberg, S., \& Veenstra, R. (2010). Basking in reflected glory and its limits: Why adolescents hang out with popular peers. Journal of Research on Adolescence, 20, 942-958.

Dijkstra, J. K., Lindenberg, S. M., \& Veenstra, R. (2008). Beyond the classroom norm: The influence of bullying of popular adolescents and its relation to peer acceptance and rejection. Journal of Abnormal Child Psychology, 36, 1289-1299.

Dishion, T. J., \& Tipsord, J. M. (2011). Peer contagion in child and adolescent social and emotional development. Annual Review of Psychology, 62, 189-214.

Ellis, B. J., Del Giudice, M., Dishion, T. J., Figureredo, A. J., Gray, P., Griskevicius, V., Hawley, P. H., Jacobs, W. J., James, J., Volk, A. A., \& Wilson, D. S. (2012). The evolutionary 
basis of risky adolescent behavior: Implications for science, policy, and practice. Developmental Psychology, 48, 598-623.

Ellis, W. E., \& Zarbatany, L. (2007). Peer group status as a moderator of group influence on children's deviant, aggressive, and prosocial behavior. Child Development, 78, 12401254.

Espelage, D. L., Holt, M. K., \& Henkel, R. R. (2003). Examination of peer-group contextual effects on aggression during early adolescence. Child Development, 74, 205-220.

Farmer, T. W., Leung, M., Pearl, R., Rodkin, P. C., Cadwallader, T. W., \& Van Acker, R. (2002). Deviant or diverse peer groups? The peer affiliations of aggressive elementary students. Journal of Educational Psychology, 94, 611-620.

Garandeau, C. F., Ahn, H.J., \& Rodkin, P.C. (2011). The social status of aggressive students across contexts: The role of classroom status hierarchy, academic achievement, and grade. Developmental Psychology, 47, 1699-1710.

Gest, S. D., \& Rodkin, P. C. (2011). Teaching practices and elementary classroom peer ecologies. Journal of Applied Developmental Psychology, 32, 288-296.

Gronlund, N. E. (1959). Sociometry in the classroom. New York: Harper \& Brothers.

Haselager, G. J. T., Hartup,W.W., van Lieshout, C. F. M., \& Riksen-Walraven, J. M. A. (1998). Similarities between friends and nonfriends in middle childhood. Child Development, 69 , $1198-1208$

Hawley, P. H. (1999). The ontogenesis of social dominance: A strategy-based evolutionary perspective. Developmental Review, 19, 97-132

Kupersmidt, J. B., DeRoiser M. E., \& Patterson, C. P. (1995). Similarity as the basis for children's friendships: The roles of sociometric status, aggressive and withdrawn 
behavior, academic achievement, and demographic characteristics. Journal of Social and Personal Relationships, 12, 439-452.

LaFontana, K. M., \& Cillessen, A. H. N. (2010). Developmental changes in the priority of perceived status in childhood and adolescence. Social Development, 19, 130-147.

Marks, P. E. L., Cillessen, A. H. N., \& Crick, N. R. (2012). Popularity contagion among adolescents. Social Development, 21, 501-521.

Mathys, C., Burk, W. J., \& Cillessen, A. H. N. (2013). Popularity as a moderator of peer selection and socialization of adolescent alcohol, marijuana, and tobacco use. Journal of Research on Adolescence.

Newcomb, A. F., \& Bagwell, C. L. (1995). Children's friendship relations: A meta-analytic review. Psychological Bulletin, 117, 306-347.

Patterson, G. R., Reid, J. B., \& Dishion, T. J. (1992). Antisocial boys. Eugene, OR: Castalia.

Peters, E., Cillessen, A.H.N, Riksen-Walraven, J.M., \& Haselager, G. J. T. (2010). Best friends' preference and popularity: Association with aggression and prosocial behavior. International Journal of Behavioral Development, 34, 398-405.

Poulin, F., \& Boivin, M. (2000). The role of proactive and reactive aggression in the formation and development of boys friendships. Developmental Psychology, 36, 233-240.

Rodkin, P. C., Farmer, T. W., Pearl, R., \& Van-Acker, R. (2000). Heterogeneity of popular boys: Antisocial and prosocial configuration. Developmental Psychology, 36, 14-24.

Rodkin, P. C., Ryan. A. M.., Jamison, R., \& Wilson, T. (2012). Social goals, social behavior, and social status in middle childhood. Developmental Psychology, doi: 10.1037/a0029389.

Ripley, R. M., Snijders, T. A.B., and Preciado, P. 2011. Manual for SIENA version 4.0 (version September 22, 2012). Oxford: University of Oxford, Department of 
Statistics; Nu_eld College. http://www.stats.ox.ac.uk/siena/

Sandstrom, M. J., \& Cillessen, A. H. N. (2006). Likeable versus popular: Distinct implications for adolescent adjustment. International Journal of Behavioral Development, 30, 305-314.

Schaefer, D. R., Light, J. M., Fabes, R. A., Hanish, L. D., \& Martin, C. M. (2010). Fundamental principles of network formation among preschool children. Social Networks, 32, 61-71.

Schwartz, D., \& Gorman, A. H. (2011). The high price of high status - Popularity as a mechanism of risk. In A. Cillessen, D. Schwartz, \& L. Mayeux (Ed.), Popularity in the peer system (pp. 245-270). New York: Guilford.

Shi, B., \& Xie, H. (2012). Popular and nonpopular subtypes of physically aggressive preadolescents: Continuity of aggression and peer mechanisms during the transition to middle school. Merrill-Palmer Quarterly, 58, 530-553.

Sijtsema, J. J., Lindenberg, S. M., \& Veenstra, R. (2010). Do they get what they want or are they stuck with what they can get? Testing homophily against default selection for friendships of highly aggressive boys. The TRAILS study. Journal of Abnormal Child Psychology, 38, 803-813.

Sijtsema, J. J., Ojanen, T., Veenstra, R., Lindenberg, S., Hawley, P. H., \& Little, T. D. (2010). Forms and functions of aggression in adolescent friendship selection and influence: A longitudinal social network analysis. Social Development, 19, 515-534.

Snijders, T. A. B., van de Bunt, G. G., \& Steglich, C. E. G. (2010). Introduction to actor-based models for network dynamics. Social Networks, 32, 44-60.

Veenstra, R., \& Dijkstra, J.K. (2011). Transformations in adolescent peer networks. In B. Laursen \& W.A. Collins (Eds.), Relationship pathways: From adolescence to young adulthood (pp. 135-154). Los Angeles, CA: Sage 
Veenstra, R., Dijkstra, J. K., Steglich, C., \& Van Zalk, M. (2013). Network-behavior dynamics. Journal of Research on Adolescence.

Veenstra, R. \& Steglich, C. (2012).Actor-based model for network and behavior dynamics. In B. Laursen, T.D. Little, \& N.A. Card (Eds.), Handbook of developmental research methods (pp 598-618). New York, NY: Guilford.

Witvliet, M., Olthof, T., Hoeksma, J. B., Goossens, F. A., Smits, M. S. I., \& Koot, H. M. (2010). Peer group affiliation of students: The role of popularity, likeability, and behavioral similarity in bullying. Social Development, 19, 285-303. 
Table 1.

Means of Friendship Network Characteristics and Changes Across Three Observation Points

\begin{tabular}{lccc}
\hline & Time 1 & Time 2 & Time 3 \\
\hline Density & $.40(.12)$ & $.39(.10)$ & $.41(.08)$ \\
Reciprocity & $.65(.06)$ & $.66(.06)$ & $.65(.05)$ \\
Transitivity & $.70(.19)$ & $.75(.32)$ & $.87(.47)$ \\
Number of Ties & $185(71.70)$ & $180(54.43)$ & $188(59.58)$ \\
Number of Pupils & $22.23(3.56)$ & $22.23(3.40)$ & $22.31(3.53)$ \\
Missing fraction & $12 \%(8 \%)$ & $10 \%(6 \%)$ & $12 \%(8 \%)$ \\
Network Changes & Time 1 -Time 2 & Time 2 - Time 3 & Time 1 - Time 3 \\
$\quad$ Number of Leavers & $0.54(0.95)$ & $1.15(1.83)$ & $1.50(2.42)$ \\
$\quad$ Number of Joiners & $0.54(0.95)$ & $0.85(1.32)$ & $1.54(2.28)$ \\
$\quad$ Number of Stayers & $21.69(3.00)$ & $21.08(3.19)$ & $20.65(3.01)$ \\
$\quad$ Jaccard Index & $0.59(0.07)$ & $0.57(0.07)$ & - \\
$\quad$ Hamming distances & $93.23(35.37)$ & $98.62(35.82)$ & - \\
\hline
\end{tabular}

Note. The values in this table were based on 26 classrooms included in SIENA analyses. Values in parentheses are standard deviations. A total of 14 students left the network between Time 1 and Time 2, which means less than one leaver on average within a classroom $(M=0.54)$. A total of 14 students joined the network between Time 1 and Time 2, which means less than one joiner on average within a classroom $(\mathrm{M}=0.54)$. 
Table 2.

Means of Behaviors and Status Distribution and Changes Across Three Observation Points

\begin{tabular}{|c|c|c|c|}
\hline & Time 1 & Time 2 & Time 3 \\
\hline \multicolumn{4}{|l|}{ Mean of Behaviors } \\
\hline Aggression & $1.84(0.27)$ & $1.83(0.35)$ & $1.88(0.33)$ \\
\hline Prosociality & $2.00(0.27)$ & $1.94(0.33)$ & $2.03(0.31)$ \\
\hline Popularity & $1.92(0.27)$ & $1.92(0.21)$ & $2.00(0.18)$ \\
\hline Preference & $2.04(0.26)$ & $2.03(0.21)$ & $2.08(0.25)$ \\
\hline \multicolumn{4}{|c|}{ Percentages of Actors in Each Category } \\
\hline Aggression: (Category 1) & 41.5 & 42.6 & 42.9 \\
\hline (Category 2) & 37.8 & 34.2 & 33.2 \\
\hline \multirow{2}{*}{$\begin{array}{r}\text { (Category 3) } \\
\text { Prosociality: (Category 1) }\end{array}$} & 20.7 & 23.2 & 23.9 \\
\hline & 32.9 & 36.1 & 35.1 \\
\hline (Category 2) & 33.1 & 31.5 & 33.7 \\
\hline (Category 3) & 34.0 & 32.4 & 31.3 \\
\hline Popularity : (Category 1) & 39.6 & 38.5 & 38.0 \\
\hline (Category 2) & 31.3 & 32.1 & 31.6 \\
\hline \multirow[b]{2}{*}{ Preference : (Category 1) } & 29.2 & 29.4 & 30.4 \\
\hline & 28.1 & 30.3 & 29.2 \\
\hline (Category 2) & 41.1 & 37.7 & 35.4 \\
\hline \multirow[t]{2}{*}{ (Category 3) } & 30.8 & 32.0 & 35.4 \\
\hline & Time $1-$ & e 2 & 2 - Time 3 \\
\hline Aggression & $6.27(2$ & & $65(2.54)$ \\
\hline Prosociality & 7.85 & & $27(3.85)$ \\
\hline Popularity & $6.96(2$ & & $15(2.80)$ \\
\hline Preference & $7.08(3$ & & $62(2.35)$ \\
\hline
\end{tabular}


Fraction Stable Actors

Aggression

Prosociality

Popularity

Preference

Percentages of actors who increased

Aggression

Prosociality

Popularity

Preference

Percentages of actors who decreased

Aggression

Prosociality

Popularity

Preference

Similarity Indices

Aggression

Prosociality

Popularity

Preference

$\begin{array}{ll}71 \%(11 \%) & 68 \%(13 \%) \\ 66 \%(17 \%) & 67 \%(17 \%) \\ 68 \%(12 \%) & 72 \%(11 \%) \\ 67 \%(24 \%) & 65 \%(11 \%)\end{array}$

10.83

13.83

11.53

14.70

12.96

13.97

12.96

14.85

11.40

10.48

14.81

8.59

12.39

7.86

12.96

12.37

Note. The values in this table were based on 26 classrooms included in SIENA analyses. Values in parentheses are standard deviations. 


\section{Table 3.}

Correlations among Popularity, Aggression, Prosociality, Preference, and Gender

\begin{tabular}{|c|c|c|c|c|c|c|c|c|c|c|c|c|c|}
\hline & 1 & 2 & 3 & 4 & 5 & 6 & 7 & 8 & 9 & 10 & 11 & 12 & 13 \\
\hline 1. Popularity T1 & - & & & & & & & & & & & & \\
\hline 2. Popularity $\mathrm{T} 2$ & $.85 * *$ & - & & & & & & & & & & & \\
\hline 3. Popularity T3 & $.81 * *$ & $.84 * *$ & - & & & & & & & & & & \\
\hline 4. Aggression $\mathrm{T} 1$ & $.11 * *$ & .05 & .03 & - & & & & & & & & & \\
\hline 5. Aggression $\mathrm{T} 2$ & $.17 * *$ & $.11 * *$ & $.10^{*}$ & $.87^{* *}$ & - & & & & & & & & \\
\hline 6. Aggression T3 & $.17 * *$ & $.10 *$ & $.13^{* *}$ & $.81^{* *}$ & $.85^{* *}$ & - & & & & & & & \\
\hline 7. Prosociality $\mathrm{T} 1$ & $.25 * *$ & $.26^{* *}$ & $.31 * *$ & $-.63^{* *}$ & $-.61^{* *}$ & $-.57^{* *}$ & - & & & & & & \\
\hline 8. Prosociality $\mathrm{T} 2$ & $.17 * *$ & $.25^{* *}$ & $.26^{* *}$ & $-.58^{* *}$ & $-.60^{* *}$ & $-.58^{* *}$ & $.80^{* *}$ & - & & & & & \\
\hline 9. Prosociality T3 & $.24 * *$ & $.31 * *$ & $.32 * *$ & $-.55^{* *}$ & $-.56^{* *}$ & $-.57^{* *}$ & $.79^{* *}$ & $.84^{* *}$ & - & & & & \\
\hline 10. Preference $T 1$ & $.50 * *$ & $.55^{* *}$ & $.55^{* *}$ & $-.46^{* *}$ & $-.39^{* *}$ & $-.34^{* *}$ & $.64^{* *}$ & $.56^{* *}$ & $.50^{* *}$ & - & & & \\
\hline 11. Preference T2 & $.52 * *$ & $.60 * *$ & $.58 * *$ & $-.41^{* *}$ & $-.39^{* *}$ & $-.32^{* *}$ & $.59^{* *}$ & $.60^{* *}$ & $.55^{* *}$ & $.82^{* *}$ & - & & \\
\hline 12. Preference T3 & $.53 * *$ & $.60 * *$ & $.61 * *$ & $-.34^{* *}$ & $-.31^{* *}$ & $-.34^{* *}$ & $.56^{* *}$ & $.53^{* *}$ & $.56^{* *}$ & $.75^{* *}$ & $.80^{* *}$ & - & \\
\hline 13. Gender $(1=$ Female $)$ & .04 & .07 & $.08 *$ & $-.17^{* *}$ & $-.16^{* *}$ & $-.15^{* *}$ & $.28^{* *}$ & $.28^{* *}$ & $.26^{* *}$ & .08 & .03 & .05 & - \\
\hline
\end{tabular}

Note. The values in this table were based on 26 classrooms included in SIENA analyses. Popularity, aggression, prosociality, and preference were based on proportion scores. $* p<.05$. ** $p<.01$. 
Table 4.

SIENA Estimates for Selection and Socialization Effects among Fifth Grade Friendship

Networks $(N=613)$

\begin{tabular}{lll}
\hline & Est. (b) & SE \\
\hline Control Variables & & \\
Outdegree & $-2.01^{* * *}$ & 0.13 \\
Reciprocity & $0.49^{* * *}$ & 0.04 \\
Transitive ties & $1.45^{* * *}$ & 0.13 \\
Balance & $0.04^{* * *}$ & 0.00 \\
Female ego & $0.08^{*}$ & 0.03 \\
Female alter & $-0.07^{*}$ & 0.03 \\
Same Gender & $0.37^{* * *}$ & 0.03 \\
Preference ego & $0.16^{* * *}$ & 0.05 \\
Preference alter & 0.04 & 0.04 \\
Similarity in Preference & $0.15^{*}$ & 0.07
\end{tabular}

\section{Selection Effects}

Ego Effects: Do some youth tend to nominate more friends?

$\begin{array}{lcc}\text { Aggressive youth } & 0.14 * * * & 0.04 \\ \text { Prosocial youth } & 0.01 & 0.04 \\ \text { Popular youth } & -0.07 & 0.04\end{array}$

Alter Effects: Do some youth tend to receive more friendship nominations?
Aggressive youth
$-0.11 * * * \quad 0.03$
Prosocial youth
$0.02 \quad 0.03$
Popular youth
$0.15 * * * \quad 0.03$

Similarity Effects: Do youth with similar attributes tend to form friendships?
Aggressive youth
$0.10 \quad 0.06$
Prosocial youth
$0.21 * * * \quad 0.06$
Popular youth
$0.43 * * * \quad 0.06$

Do aggressive and prosocial youths with similar popularity levels choose each other as friends?
Aggressive ego $\times$ prosocial alter $\times$ popular-similarity
$0.16^{*}$
0.08
Prosocial ego $\times$ aggressive alter $\times$ popular-similarity
$-0.08$
0.08

(cont'd) 
Socialization Effects

Aggression

Linear shape

Quadratic shape

Aggressive influence (average similarity)

Effect preference on aggression

Effect gender (female) on aggression

Prosociality

Linear shape

Quadratic shape

Prosociality influence (average similarity)

Effect preference on prosociality

Effect gender (female) on prosociality

Popularity

Linear shape

Quadratic shape

Popularity influence (average similarity)

Effect preference on popularity

Effect gender (female) on popularity
Est. (b) SE

$\begin{array}{ll}-0.11 & 0.09\end{array}$

$0.59 * * * \quad 0.17$

$3.53 * * * \quad 0.79$

$-0.20 \quad 0.14$

$\begin{array}{ll}0.09 & 0.18\end{array}$

$\begin{array}{ll}-0.35 * * * & 0.09 \\ 0.44 * * * & 0.13 \\ 3.66 * * * & 0.72 \\ 1.01 * * * & 0.21 \\ 0.16 & 0.16\end{array}$

$-0.22 \quad 0.13$

$0.63 * * * \quad 0.19$

$5.53 * * * \quad 1.08$

$1.50 * * * \quad 0.32$

$\begin{array}{ll}-0.09 & 0.20\end{array}$

Note. $* p<.05 . * * * p<.001$. SIENA models include 36 parameters, and so degrees of freedom for $t$-tests of parameter estimates are $d f=N-$ parameters $=613-36=577$. 
Table 5.

Influence of Peers (Alters) on Youth's (Ego's) Behaviors and Popularity on the Three Point Scale.

\begin{tabular}{lrrrr}
\hline \multirow{2}{*}{ Alters } & & \multicolumn{3}{c}{ Ego } \\
\cline { 3 - 5 } Aggression & 1 & 1 & 2 & 3 \\
& 2 & 1.90 & -0.39 & -1.50 \\
Prosociality & 3 & 0.13 & 1.37 & 0.27 \\
& & -1.63 & -0.39 & 2.03 \\
Popularity & 1 & & & -2.06 \\
& 2 & 0.45 & -0.33 & -0.23 \\
& 3 & -1.38 & -0.33 & 1.60 \\
& & & & -2.69 \\
& 1 & 3.15 & -0.40 & 0.08 \\
& 2 & 0.39 & 2.37 & 2.84
\end{tabular}

Note. Each row represents the behavior and popularity of youth's friends in general. Each column represents youth's tendency to change their behavior or popularity towards a certain level. 